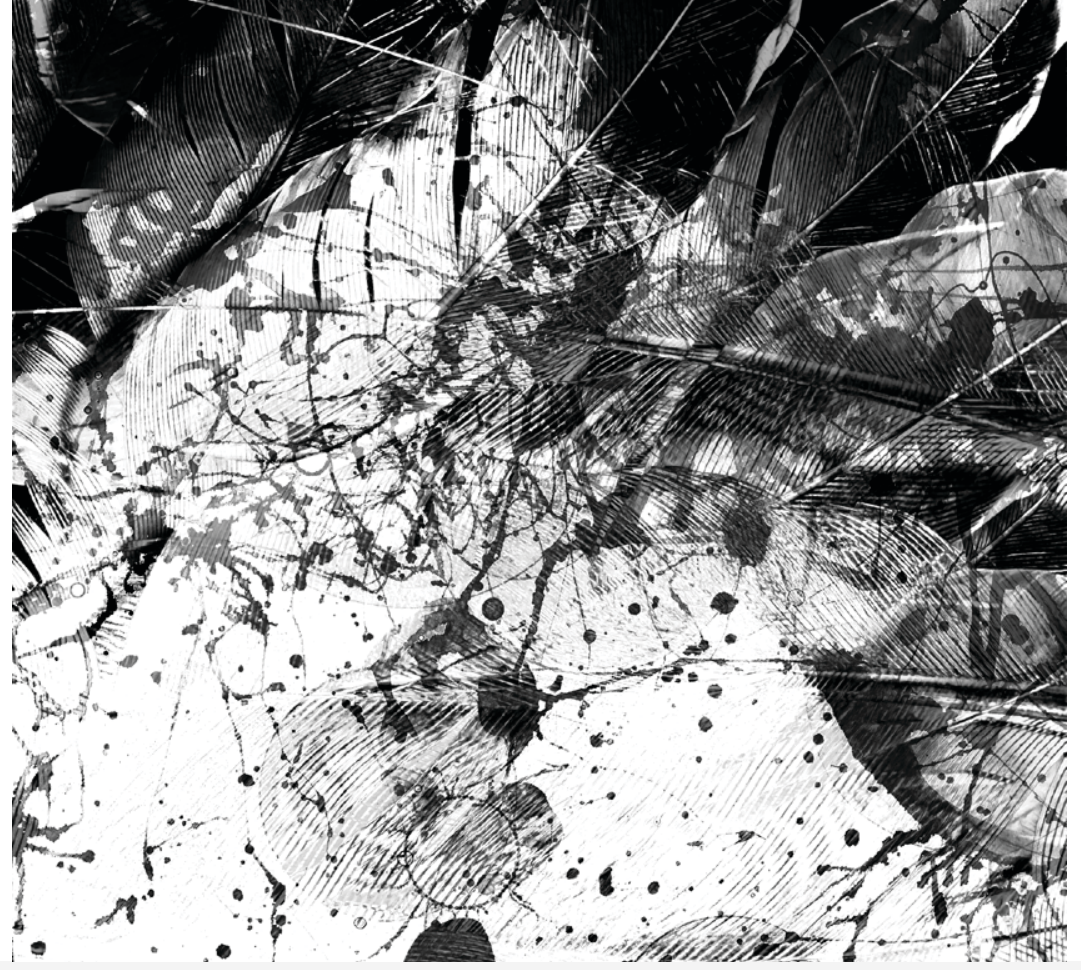

\title{
MUJER, VIOLENCIA Y CINE COLOMBIANO DEL SIGLO XX ${ }^{1}$
}

COLOMBIAN WOMAN, VIOLENCE AND CINEMA OF THE 20TH CENTURY

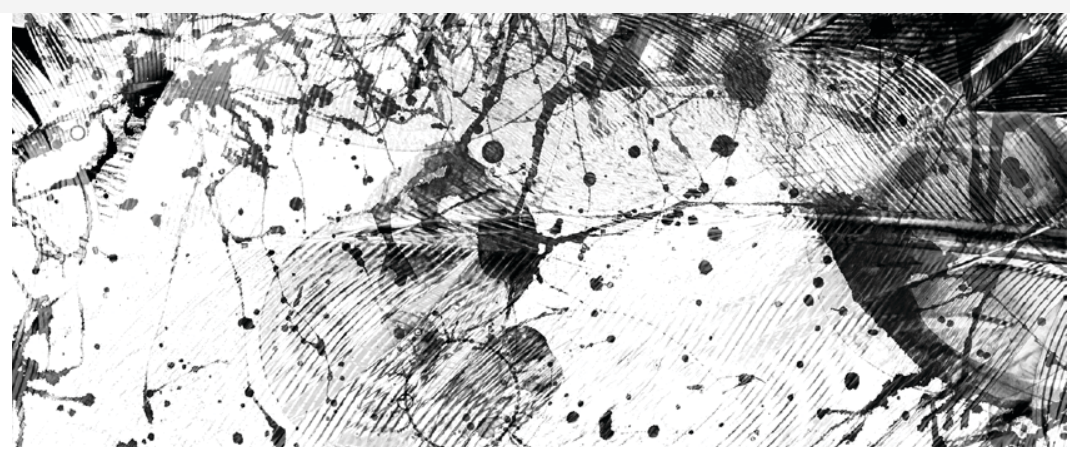

Por

Diana Alejandra Gutiérrez Ortiz ${ }^{2}$ Universidad Autónoma de Occidente dianaalejandra23@hotmail.com 
Resumen: El artículo plantea una relectura a un corpus seleccionado de películas colombianas del siglo XX que abordan el tema de la violencia bipartidista y el conflicto social, dada su particular relación con las nuevas formas de representación de la mujer como personaje central del relato. Con el incremento de estímulos económicos por parte de iniciativas gubernamentales, se evidenciaron nuevas apuestas estéticas que visibilizaron una mayor presencia de la mujer en la filmografía colombiana de los años 60 en adelante y es desde esta reflexión que se desarrolla el análisis planteado en el texto.

Palabras clave: mujeres y cine colombiano, violencia y cine, cine colombiano siglo $\mathrm{XX}$, FOCINE, el bogotazo.

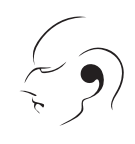

\begin{abstract}
The article proposes a rereading of a selected corpus of Colombian films of the 20th century that deal with the subject of bipartisan violence and social conflict, given their particular relationship with the new forms of representation of women as the central character of the story. With the increase in economic stimuli from government initiatives, new aesthetic bets became evident that made visible a greater presence of women in Colombian filmography from the 1960s onwards and it is from this reflection that the analysis set out in the text is developed.
\end{abstract}

Keywords: Women and Colombian cinema, violence and cinema, 20th century Colombian cinema, FOCINE. 
Partimos de la particular inmersión que tuvieron las mujeres colombianas en asuntos políticos durante el enfrentamiento entre liberales y conservadores a mediados de siglo XX en Colombia, para llamar la atención sobre aspectos relevantes que atañen a la producción cinematográfica nacional durante los años ochenta. Los datos acerca de la participación de la mujer en asuntos de guerra y enfrentamientos a lo largo de uno de los periodos de violencia política más álgido en la historia en Colombia, apuntan a diversos roles o perfiles, aquellos más tradicionales como en el caso de las madre-esposas, hasta las mujeres más combativas que formaron parte de algún bando político y rumiaban el mismo odio de sus esposos por los contrarios.

Considerada como consecuencia del surgimiento del discurso fílmico colombiano sobre La Violencia ${ }^{3}$, principalmente la de los años cincuenta, la transformación del rol de la mujer al interior de los relatos se produce cuando el cine de la década del ochenta busca retomar historias del pasado, constituyendo los primeros intentos de cine político institucional en el país.

Encontramos específicamente en las películas que se estrenan en los años ochenta en Colombia, una preponderancia de cuestiones relacionadas con el acontecer político, las consecuencias de las luchas de poder y el enfrentamiento entre diferentes fuerzas sociales y económicas. La mujer participa de estos relatos ya no desde la pasividad que la caracterizó en décadas anteriores, como utilerías del drama, donde fueron protagonistas de historias alejadas de las intenciones que exploran nuevos escenarios de participación. En los relatos tradicionales, los personajes femeninos se circunscribían al ámbito privado que toma como centro el hogar y la familia, limitando el papel de la mujer a estos contextos ${ }^{4}$.

Circulan con abundancia las historias de mujeres que convirtieron sus casas en refugios de enfermos y alimentaban a los heridos hasta devolverlos sanos y enérgicos al campo de batalla:

En las ciudades, la mujer liberal centró su apoyo en la consecución de drogas, para lo que fue necesario que, en sus casas, se multiplicaran las dolencias simuladas, tanto como sus visitas a la botica. La ropa blanca se esfumó de los almacenes y la de cama se hizo escasa en los hogares cuando, deshilachada por las pacientes manos femeninas, salió para las zonas de guerra convertida en gasa. (Jaramillo, 1995, p.372).

Pocas mujeres del ejército Conservador quedan registradas en la historia como abanderadas de su causa y partido, pues la mayor parte de jefes de partido eran hombres, y precisamente en un sentido ideológico el rol femenino se asumía a partir de la sumisión y subordinación absoluta a las órdenes de sus esposos; caso contrario al de las mujeres que en las filas del liberalismo marcharon con revólver al cinto, llevando la bandera de su partido y defendiendo con su propio cuerpo los intereses de su colectividad: 
(...) En él [partido Liberal] encontramos mujeres que asumieron como oficiales la conducción de tropas en los cuerpos regulares del Ejército Restaurados, y mujeres que, como guerrilleras, lucharon en la base de la organización militar. Como oficiales podemos citar a: Candelaria Pachón, muerta en la batalla de Terán; Ana María Valencia, abanderada del Batallón Pamplona, muerta en Palonegro; Inés Melgar, segundo jefe del batallón Gaitán de Panamá; Carmen Bernal, corneta de órdenes del general Hermógenes Gallo, y Mila Arellano, quien siendo hija de un general ecuatoriano, fue jefe de la columna Parra que operó en la zona fronteriza con este país. (Jaramillo, 1995, p.376)

En relación al cine colombiano contemporáneo que toma como referencia mujeres involucradas en la violencia colombiana del siglo XX, podemos resaltar que, de manera singular a partir de la Ley 615 de 2003 o Ley del Cine, la mayoría de los proyectos cinematográficos se han dedicado a retomar el fenómeno del narcotráfico de los años ochenta. Sin embargo, surge una historia en contravía a esta hegemonía: la biografía de la Sargento Matacho ${ }^{5}$, la cual se suma al binomio violencia-cine y se detiene en la vida de esta guerrillera que se conoce en la década de los cincuenta y sirve como fuente para referenciar otra de las heroínas míticas de la violencia bipartidista, quien al igual que otras mujeres, son provocadas y lanzadas a la guerra al ver cómo se pone en juego la vida de su familia.

En cualquier caso, las mujeres se encargaron de demostrar que la guerra ya no era asunto de los hombres, de sus hermanos, su marido, padres o hijos, sino un asunto que las comprometía directamente a ellas y las empujaba a esa batalla por la restitución de su dignidad, la sobrevivencia de la familia y la defensa de su comunidad. Y lo hicieron a su manera. Algunas, como Rosalba Velásquez, llamada "Sargento Matacho", ante el asesinato de su hombre, juraron venganza y se enrolaron en las bandas y cuadrillas que encontraron en su camino; otras, como Graciela Loayza, ante la arremetida del terror oficial, engrosaron las guerrillas de resistencia liberal; algunas, como Laura, la mujer de Alfonso Castañeda ("Richard"), encontraron en el movimiento revolucionario de las guerrillas comunistas provenientes del sur del Tolima, la mejor manera de hacer y hacerse justicia. (Álvarez, 1995, p.484)

También referenciada en la historia de las mujeres en guerra ${ }^{6}$ encontramos a "La Negra Petronila", quien luego de la Toma de Honda en 1901, merece llevar en las primeras filas las banderas de su partido, el Liberal, debido a que, en una de las batallas libradas entre Ambalema y Gramalote con los conservadores, Petronila se volvió a recoger la bandera liberal entre los muertos, demostrando su coraje y compromiso ideológico con su grupo. Como esta historia, se multiplican los casos en los que la mujer avanza en el conflicto como combatiente, en menor porcentaje que los hombres, pero destacándose por su rol fundamental en las batallas y luchas que determinaron el devenir histórico del siglo XX. 
Por otro lado, ya no como guerrilleras o en grupos al margen de la ley, encontramos la historia de la participación de la mujer colombiana en la esfera política o pública, haciendo parte de instituciones estatales y educativas de renombre a nivel nacional. Durante el Frente Nacional (1958-1974) fue cada vez más usual oír hablar de alcaldesas, gobernadoras, concejales, diputadas y senadoras. Luego de la aprobación del voto femenino y de obtener derechos políticos en 1957, las transformaciones se hicieron notar en diferentes esferas pues desde el hogar, espacio habitual de ejercicio de las mujeres con sus familias, hasta el espacio industrial, comercial y estatal, la inclusión de la mujer en diversos escenarios cambió las lógicas de varios de los procesos en los que la mirada masculina tenía ya establecida una hegemonía.

Por su cuenta, las mujeres no se asumieron de manera total a partir del siglo XX como una parte esencial en la transformación social, pues aun cuando el espacio legítimo para su participación constitucional estuviese establecido en la práctica y el ejercicio democrático que les correspondió, no hubo mayor modificación en cuanto a los resultados del ejercicio deliberativo y de participación que se venía desarrollando, con los hombres como únicos jefes, antes del 57.

Lo que no se puede afirmar es si en efecto la integración a nuevos espacios, antes negados de manera absoluta para la mujer como el caso del sector público, redundó en el cambio del panorama político y económico de la sociedad colombiana a partir de mediados del siglo XX. Lo que sí podemos entrever es que, como pieza estratégica para la consecución de diversos objetivos por parte de cada grupo de interés político, la mujer fue trascendente y determinante, pues se manifestaron diferentes intensiones en la búsqueda de la paz como la realización de la Asamblea Nacional Constituyente, la cual expidió la actual Constitución de 1991.

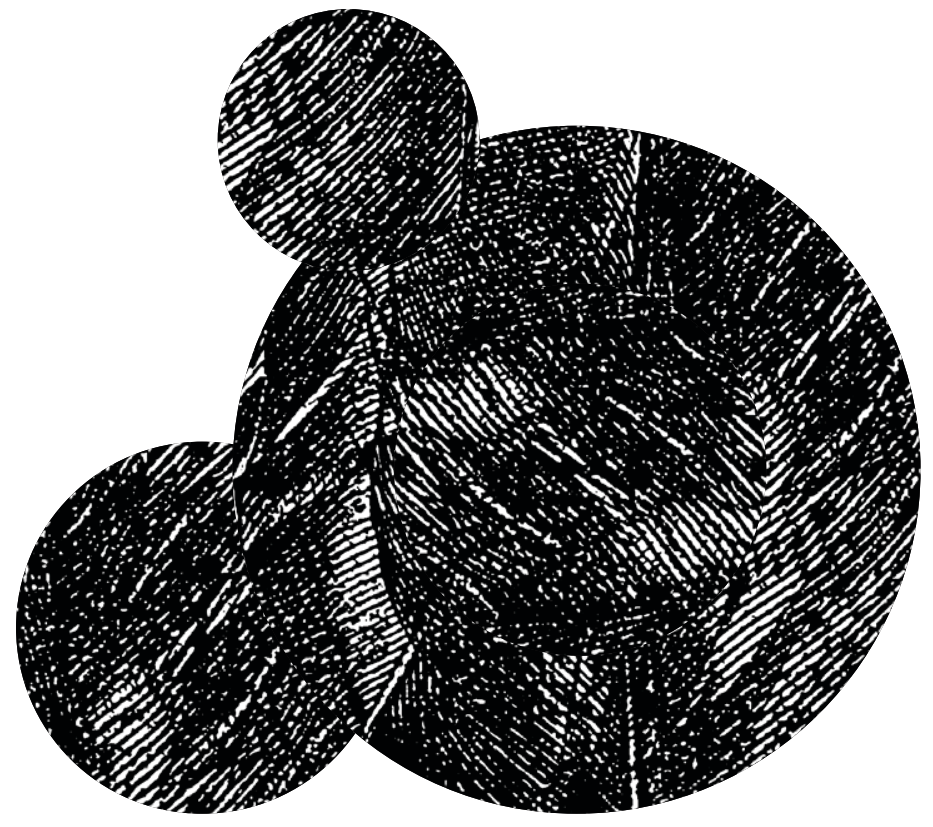

Actualmente los derechos de las mujeres acaban de ser perfeccionados por la Asamblea Nacional Constituyente, que además suprimió las secuelas y restos de disfrute desigual de ciertos derechos sociales. No obstante, la condición femenina, en tanto tiene que ver con conductas, comportamientos y costumbres larvadas durante largos periodos, está aún sometida a incontables y poderosos problemas que tocan con su imagen, con los sistemas de valores, con su sexualidad, que mantienen en amplios núcleos de la población, la idea de que es un ser débil, sometido a los designios del hombre, objeto de manipulación morbosa, etc. (Acevedo, 1995, p.477) 


\section{La representación de la violencia del siglo XX en el cine colombiano}

Desde los inicios del cine se evidenció que las ciudades más desarrolladas en cuanto a cadenas productivas, con procesos de industrialización importantes y por ende con mayores posibilidades de financiación para este nuevo invento - concebido inicialmente como científico, posteriormente de valor artístico-, iniciaron un proceso de producción de películas que sobre todo se extendió en el terreno documental. Paranaguá (2003) señala que este es un rasgo común del primer cine latinoamericano durante el período silente. Mientras que la producción de ficción resultó discontinua y precaria, el cine documental tuvo un desarrollo relevante en varios países de la región.

La exploración de nuevas formas de representación como la argumental describió aspectos de la vida social nacional, convirtiéndose la política y la relación entre el Estado y la población civil en temas recurrentes ya desde los años de 1920, cuando películas como El drama del 15 de octubre en 1915 de los hermanos Di Doménico, aparecieron reconstruyendo historias y sucesos sociopolíticos. En este caso, se trató de la muerte del general Rafael Uribe Uribe, cuyo impacto en el público y la sociedad en general fue alarmante, debido no solo a la novedad del cine como invento sino a la manera como los directores abordaron aspectos que se encontraban en el corazón mismo de la disputa, tales como discursos presidenciales, registro de votaciones del Gobierno, relaciones entre contextos urbanos y rurales y, en general, todo lo que implicaba ver por primera vez en pantalla registros de un país que se vivía y sufría a diario. Juana Suárez, en el apartado de "Caos, mitos y silencios, el primer cine colombiano”, lo plantea de la siguiente forma:

El drama del 15 de octubre cobra singular importancia no solo por su aparente primer lugar en la cinematografía colombiana, sino porque desde entonces, plantea una serie de premisas que aún recorren el cine colombiano: la representación de la violencia, la contradictoria recepción del cine nacional por el mismo público del país y los avatares de producción y distribución. (Suárez, 2009, p.28)

La violencia es materia de representación en el cine colombiano ante los constantes enfrentamientos y luchas que se desarrollan en cada época, cuando la desigualdad, la crisis del aparato estatal y la cada vez más amplia brecha entre ricos y pobres y su consiguiente inequidad social, estallan en un conflicto en el que participan, además de los afectados, los intereses de los grandes grupos económicos y políticos tanto nacionales como extranjeros. Desde las más sencillas historias de amor hasta los grandes dramas sociales contienen en su narrativa alusiones a la realidad nacional, la estratificación socioeconómica de los personajes, los paisajes y escenografías, la música, las apuestas estéticas, todo esto compone lo que para la semiótica es materia de estudio y análisis pues transmite mensajes de tipo político de manera directa, indirecta, intencional o casual. 
El afán clasificatorio de los períodos de la violencia en Colombia sugiere diversas maneras de organizar por grupos los fenómenos que rodean cada uno de los hechos. Algunos estudiosos definen la primera violencia como aquella situada a partir de la muerte de Jorge Eliécer Gaitán a finales de los cuarenta, pues es en este momento cuando acontecimientos posteriores alcanzan los índices más altos de víctimas y caos social: el auge de las facciones guerrilleras y la respuesta paramilitar que se desata en los años sesenta, el desplazamiento forzoso de la población rural y la avanzada de las mafias en ciudades como Medellín y Cali, desde mediados de los ochenta ${ }^{7}$.

Sin embargo, a los efectos de nuestra investigación hemos tomado como referencia la violencia que transcurre desde principios de siglo XX, específicamente en las décadas del veinte y treinta, así como los acontecimientos transitorios de los años cuarenta hasta finalizar en 9 de abril de 1948 con el Bogotazo. Este corte obedece, principalmente, al objetivo de analizar la cinematografía colombiana de los años ochenta, en la que se encuentran referentes históricos que coinciden con los tres períodos señalados: la crisis de los años 20 con la masacre de las bananeras, la época de la violencia bipartidista de los 50 y la consolidación de las guerrillas durante los años 60 y 70 .

En medio del conflicto y la violencia de las décadas del cincuenta y sesenta se producen diversos textos cinematográficos que retoman el tema de la desigualdad social y la crisis social y existencial del individuo en diversos contextos. Destacamos a continuación la obra de tres directores que, bajo la forma del documental, propusieron una lectura que nos permitirá relacionar los contenidos que antecedieron a la producción del cine de los ochenta y su cercanía al tema de la violencia.

Los trabajos documentales de Marta Rodríguez y Jorge Silva cobran importancia desde la perspectiva histórica debido a la valiosa interpretación que éstos hacen de los procesos de explotación y reclutamiento de hombres, mujeres y niños en la lucha por la tenencia de la tierra durante el siglo XX. Su largometraje documental Chircales, estrenado en 1972, cuyo proceso de investigación y filmación demandó más de seis años, permite reconocer —no solo por la envergadura del tema sino por la propuesta reflexiva e ideológica de los realizadores - una versión de la realidad con muy poco eco en la historia del cine colombiano contemporáneo: los intentos por abordar temas que giran alrededor de un cine militante, cercano a una ideología anticapitalista y que apelan mayoritariamente al modelo argumental.

Los latifundistas son vistos desde Chircales como los opresores y explotadores de los labriegos, a quienes se les reconoce su condición de víctimas que han dejado su testimonio nada más que en el celuloide. Aún hoy la relación es desigual y arbitraria entre patrón y obrero y la figura del compadrazgo es manejada en varios de los eslabones de la cadena productiva, tanto en la producción de ladrillos como se registra en Chircales, como en otros espacios de la actividad mercantil. 
como los de Gabriela Samper, Camila Loboguerrero y más recientemente Libia Stella Gómez- y a la cercanía de su trabajo a propuestas de cine documental de países latinoamericanos que, como hemos mencionado, en las décadas del sesenta y setenta se interesaron en un tipo de cine de concientización política. Rodríguez inicia su trabajo en solitario en 1987 luego de la muerte de Jorge Silva, y a partir de allí es notable la transición de su obra hacia un cine de la marginalidad, destacándose en la representación de problemáticas como la lucha por la tenencia de la tierra, la violación de los derechos humanos en comunidades campesinas y el desplazamiento forzoso, entre otros. De acuerdo con Juana Suárez, una vez fallece Silva, los trabajos de esta cineasta se enfocan primariamente en una perspectiva de mujeres bajo una mirada femenina, en Amor, mujeres y flores (1989) se aborda el tema de la industria floricultora, de los abusos contra los derechos laborales de las trabajadoras y el uso ilegal de pesticidas y químicos en los cultivos, lo que aumentaba el riesgo de enfermedades en los empleados.

El eco del trabajo de Marta Rodríguez ha permanecido a lo largo del tiempo, no solo por su empeño en acentuar la dimensión política y de denuncia social en sus trabajos sino por promover el levantamiento tanto de las minorías representadas en sus películas, como de los grupos de mujeres trabajadoras ante los actos de injusticia social. Aunque esta directora se declara abiertamente por fuera de las búsquedas del feminismo, sus proyectos cinematográficos documentales han mantenido una fuerte vinculación con posturas feministas en temas como los derechos sexuales y reproductivos, la justicia y el medioambiente.

Otro de los grandes aportes al documental colombiano de la década del sesenta lo realizó la directora Gabriela Samper, quien luego de haber pasado por el teatro y por diferentes roles en el área técnica de la realización cinematográfica, se dedicó a la dirección de trabajos que se vinculan, como los de Rodríguez y Silva, a los caracteres ideológicos y formales del Nuevo Cine Latinoamericano?.

El interés de Samper en su experiencia fílmica estuvo marcado por las inquietudes que le generaban las historias de vida de las clases populares, quienes en medio de situaciones adversas sobrevivían, deambulaban y se relacionaban entre sí en medio de diversos espacios como el barrio, el campo y las fábricas. Esta relación entre el hombre y su entorno se convierte en el eje fundamental de los textos fílmicos de Samper, quien se inclinó por un tipo de cine más intimista, el cual, partiendo de historias personales, reflexiona sobre los grandes problemas de la sociedad.

Una experiencia que coincide con las intenciones de otro director de cine latinoamericano, Jorge Prelorán, quien por varias décadas, desde mediados de los cincuenta, se dedicó a producir lo que él mismo llamó etnobiografías, buscando a través de la narración de la vida de una sola persona conocer la cultura a la que pertenecía. Felipe Montalva (2010) señala en su artículo "Jorge Prelorán, el hombre es un creador" las características fundamentales del trabajo de este documentalista, 
que busca producir cine de conocimiento del otro, de ese otro distinto cultural, social e incluso étnico. Según Prelorán (citado por Montalva, 2010): "La visión desde afuera muestra que ellos son distintos a nosotros, y como lo que nos muestran de esos otros es lo raro o lo primitivo, en esencia este cine sería básicamente xenofóbico”.

Con Páramo de Cumanday, la primera película filmada por Samper en 1965, se descubre el estilo de esta documentalista, el que se destaca por el contraste entre los diferentes temas para generar un choque en el espectador, un nivel interpretativo que recurre por un lado a la observación y exploración espacial y por otro, a la oposición como base de la narración, tal es el caso del documental El hombre de la sal $(1965)^{10}$. Con sus trabajos de denuncia documental y, específicamente con el cortometraje Los santísimos hermanos (1960), Gabriela Samper se convierte en una enemiga para el Gobierno que ya entonces perseguía a los miembros de los grupos de intelectuales de izquierda ${ }^{11}$.

Con sus películas, Rodríguez, Silva y Samper consolidaron un corpus cinematográfico significativo que sirvió como referente para generaciones posteriores de directores que abordarían temas relacionados con la violencia desde el registro argumental. Contrario al panorama que se evidenció en otros países de Latinoamérica durante la década del sesenta, en los que la voz masculina fue preponderante a la hora de encarar la producción de cine documental, el caso de Marta Rodríguez y Gabriela Samper en Colombia es destacable pues ambas directoras compartieron el vínculo con el Nuevo Cine Latinoamericano debido al corte antropológico de sus propuestas, a las motivaciones estéticas e ideológicas, y a la inclinación hacia el enfoque etnográfico de las comunidades representadas en las películas, en un contexto en el que encontramos mayoritariamente referencias a nombres como el del brasilero Glauber Rocha, los argentinos Fernando Birri, Fernando Solanas y Octavio Getino, los cubanos Tomás Gutiérrez Alea y Santiago Álvarez y los chilenos Miguel Littín y Patricio Guzmán, con escasas menciones a la producción de cine hecho por mujeres.

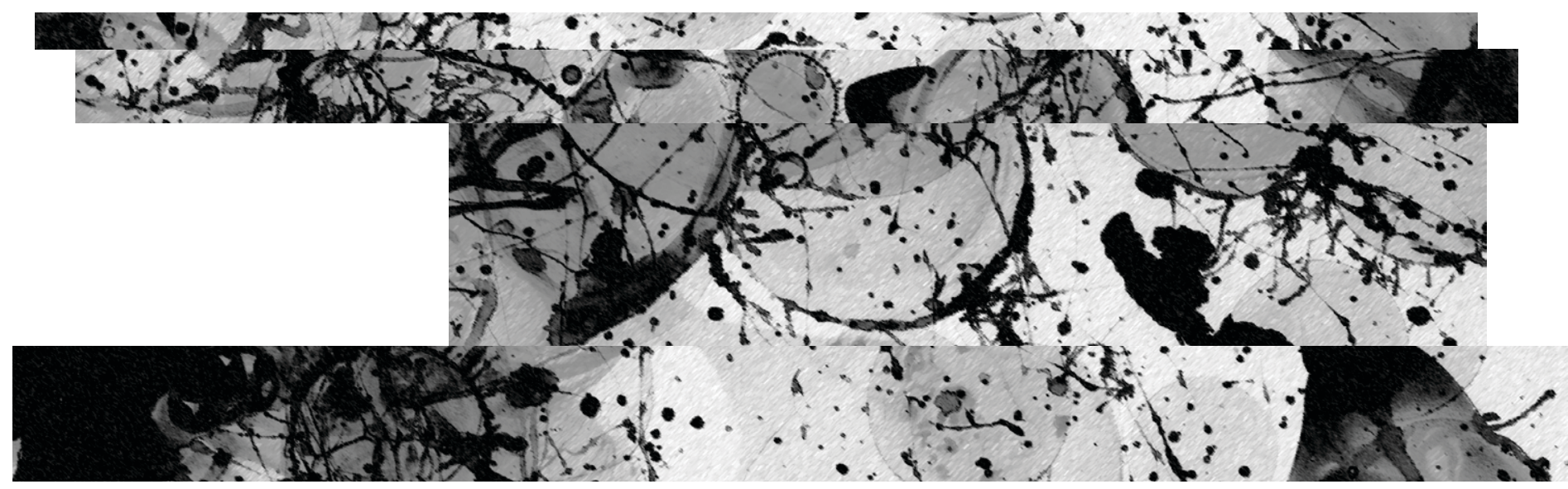


De manera aislada, y como el único caso de largometraje argumental que se refiere a los hechos de la primera violencia, aparece en la década del sesenta la película $E 1$ río de las tumbas de Julio Luzardo (1965). Este filme basa su argumento en la historia de una comunidad azotada por las tensiones entre partidos, representada por estereotipos no solo a nivel de los personajes (el bobo del pueblo, el cura, la reina de belleza, el político, el policía) sino de la caricaturización misma de los espacios. Con este filme, Luzardo aborda - aunque con algunas prevenciones y no de manera frontal - el tema de la violencia, en la medida que su propuesta estética demuestra el enrarecimiento de un entorno en el que conviven el humor y los cadáveres que bajan por el río Magdalena.

A pesar de la fallida gesta del humor en El río de las tumbas, es posible brindar otra radiografía de esta producción de Luzardo si se piensa dentro de una búsqueda de un lenguaje fílmico para representar la complejidad de La Violencia. No resulta gratuito, entonces, desglosar las palabras del director "el pueblo es el país, la violencia son los cadáveres que nadie quiere" para entender por qué el testigo central del acto de violencia brutal que marca la narrativa aparentemente encarnado en un personaje ininteligible y representado como dependiente al alcohol. "Chocho" (el personaje que estereotipa "al bobo del pueblo"), es quien descubre los cuerpos violentados y tirados de forma anónima al río. Su inhabilidad de articular, de nombrar la violencia, no es distante de la inhabilidad de las autoridades de enfrentar esta violencia. (Suárez, 2009, p.66)

Hasta 1981, cuando se estrena Canaguaro del director nacido en Chile y radicado en Colombia Dunav Kuzmanich, la violencia bipartidista no se retomaba en el cine colombiano de ficción ${ }^{12}$, probablemente por el momento crucial que atraviesa la financiación de las películas en los años setenta con la puesta en marcha de la Ley del Sobreprecio, una normativa que dio prelación a películas de temática social y de tipo urbano que no pretendieron el cuestionamiento sobre la violencia del público nacional sino el aplauso internacional con el carácter de pornomiseria de las producciones. Suárez (2009) enfatiza esta idea apoyada en la crítica de Luis Alberto Álvarez y le atribuye a Canaguaro las intenciones de un cine que busca liberarse de la esclavitud del Sobreprecio y contrarrestar propuestas fílmicas como las de Ciro Durán con la película Gamín (1977), que no acertaron en la representación de fenómenos sociales y en hechos que marcaron la violencia de mediados de siglo, pues se quedaron en un "paquete de buenas intenciones" y se limitaron al campo de la enunciación, sin profundizar en la exploración del lenguaje audiovisual y en la narrativa fílmica.

Canaguaro es la primera de las películas de la década del ochenta que aborda el tema de la violencia y lo hace a través de la historia de Canaguaro, personaje que se denomina igual al pueblo que habita; ambos, el personaje y su espacio son víctimas de las duras consecuencias que dejan la muerte de Gaitán y las operaciones guerrilleras en la zona de los llanos orientales. Desde el inicio de la narración se realizan alusiones 
directas a la figura del Gaitán libertador convirtiendo a Canaguaro en la metáfora del ideal político que representa el líder colombiano. La base argumental del filme es la desvinculación de los liberales a grupos guerrilleros, un hecho que enardece el clima político generando enfrentamientos de militantes, campesinos y miembros del Estado, que deja un desolado paisaje en el que surgen, además de las desconfianzas, los muchos muertos en cada batalla librada en Canaguaro.

La crítica de la película fue favorable y el análisis de diversos autores la ubica como la primera película de verdadera ideología política e intenciones directas hacia el cuestionamiento de la polarización partidista en Colombia de la década del cincuenta.

Pese a sus defectos técnicos — particularmente los desaciertos sonoros, pues el sonido directo aún era una imposibilidad en Colombia para ese tiempo- Canaguaro es uno de los mejores productos de los años paralelos a FOCINE y, como en el caso de muchas otras, su pronto retiro de las salas de cine deja constancia del silenciamiento sistemático de producciones sobre el tema que FOCINE también ejerció y que no tiene otro nombre sino censura por omisión. (Suárez, 2009, p.79)

Canaguaro es el mejor ejemplo e indicio que encontramos de lo que sería un referente para varios de los procesos cinematográficos de la década del ochenta: su temática se vuelve recurrente para otros directores que asumen la revisión histórica como mecanismo para revivir el problema de la violencia bipartidista.

La distancia que treinta años después del asesinato de Gaitán se establece para hablar de este fenómeno y sus consecuencias y las posibilidades de acudir a un ente estatal para la financiación de los largometrajes, o en el caso contrario, de buscar alternativas presupuestarias paralelas a los incentivos de FOCINE, son varios de los factores que determinan de manera general el grueso de la producción nacional.Y sobre los que nos hemos detenido para analizar los cambios que en los personajes femeninos importaron una mirada renovada no solo en la narrativa fílmica sino en los diversos caminos que se implementaron para realizar un número mayor respecto de décadas anteriores - de textos fílmicos que impulsaron explícitamente la función política del cine.

Ya instalados en el momento histórico de la producción de FOCINE (años ochenta) donde los fenómenos sociales están más asociados a circunstancias como las del narcotráfico, las mafias que operan en diversas regiones del país y el enfrentamiento entre cárteles de la droga y el contrabando, hay un tipo de migración del cine nacional hacia una representación de los relatos en la clave del melodrama, propia del cine de ficción.

Los antecedentes del setenta en cuanto a la producción de cine en Colombia se sustentan la mayoría en el documental como territorio para la representación; hemos señalado ya los trabajos de Marta Rodríguez y Gabriela Samper quienes, en 
consonancia con otros directores latinoamericanos, promovieron un cine de y para la militancia política. Sin embargo, en los años ochenta cuando los directores se deciden por una experimentación mayor con los géneros en el examen de la violencia del pasado, se abre un abanico de posibilidades que logra la agencia de la mujer y se manifiesta una ruptura acerca de su nuevo rol dentro del relato. Cercanas a las dinámicas del cine convencional o comercial, las películas de las que nos ocuparemos en los capítulos siguientes no se quedan en el asunto de las frustraciones domésticas de la mujer y se encaminan por el sendero de la revisión histórica.

En el filme Cóndores no entierran todos los días se reproducen con exactitud y poca cautela los efectos de la violencia bipartidista en Tuluá, un municipio del centro del Valle del Cauca. La historia parte de la muerte de Jorge Eliécer Gaitán y sus consecuencias sociales y políticas en aquel municipio. La condición de adaptación literaria de la película acerca su modo de representación al del realismo social, pues al tratarse de una ficción histórica, la narrativa conserva elementos del contexto político y cultural de la época. Es bajo esta perspectiva, que examinaremos el filme de Norden, estudiando sus condiciones de producción y la manera en que la representación de lo femenino, en el ámbito de la violencia bipartidista, adquiere un significado distinto.

En la película Carne de tu carne aparecen múltiples referencias a la época de La Violencia. El incesto que se repite en la nueva generación de la familia Velazco es el que abre la posibilidad de la metaforización ideológica, ya que con el personaje del tío Enrique, quien cuenta a sus sobrinos el pasado turbio de la familia (la relación amorosa con su hermana), se abre la puerta para que los dos hermanos adolescentes experimenten una transformación física y surrealista. El sentido alegórico del filme nos conducirá al análisis sobre las posibilidades de representación de La Violencia, acercándonos a la particularidad manifestada por este tipo de cine, de fuerte referencialidad a la literatura inglesa, en la que personajes arquetipos como el vampiro guían la narración.

El pretexto argumental de la película Confesión a Laura surge a partir de la recreación de los acontecimientos del día que mataron a Jorge Eliécer Gaitán. El estar inscrita en este momento histórico específico hace que la película contenga una fuerte carga ideológica frente al pensamiento liberal y conservador colombiano; la referencia literal a Gaitán como símbolo y mártir de la política nacional se desplaza en medio del comportamiento de los personajes. El análisis de la representación del estado de sitio en las calles de Bogotá es el detonante que nos permitirá pensar la relación entre el cine, la representación de la mujer y la violencia en Colombia.

La película María Cano no ubica como eje de su argumento la violencia bipartidista de los años cincuenta. La actividad sindical tan fuertemente marcada en los sectores productivos a inicios del siglo XX en Colombia, el nacimiento y posterior posicionamiento de cadenas como la frutícola, la industrial y la cafetera en regiones 
como Antioquia, Valle del Cauca y la zona Andina en general, hicieron que la inclusión de la mujer en espacios de laboriosidad distintos al doméstico fuese cada vez más frecuente. Por esta razón, nos ocuparemos más adelante de los hechos históricos que aparecen referenciados en el relato de María y que son tenidos en cuenta por Loboguerrero para establecer una mirada revisionista de la historia. De acuerdo a esta intención, se propone una nueva versión de los hechos, desde la cual se prepondera el rol femenino bajo las toldas del Partido Socialista en Colombia en los años veinte y treinta, lo que a su vez da apertura a la construcción de un nuevo símbolo del trabajo, la lucha y la liberación: "La flor del trabajo".

A manera de conclusión, podemos afirmar que en el examen histórico y cultural de la violencia del siglo XX en Colombia quedan al descubierto las relaciones entre las temáticas que abordan algunas películas desde la llegada de la actividad fílmica al país, todas ellas emparentadas con la visión de la problemática social y política, que más tarde serviría como referente para la consolidación del discurso fílmico sobre la violencia.

Los directores de las películas de los ochenta y noventa en el caso de María Cano, ya habían producido en los setenta importantes documentales para la historia del cine nacional. Sin embargo, es durante ésta época que se dedican a la producción de argumentales, lo que les permite abordar en un sentido menos directo, a través de una puesta en escena más sofisticada, diversas posturas en las nuevas versiones de la

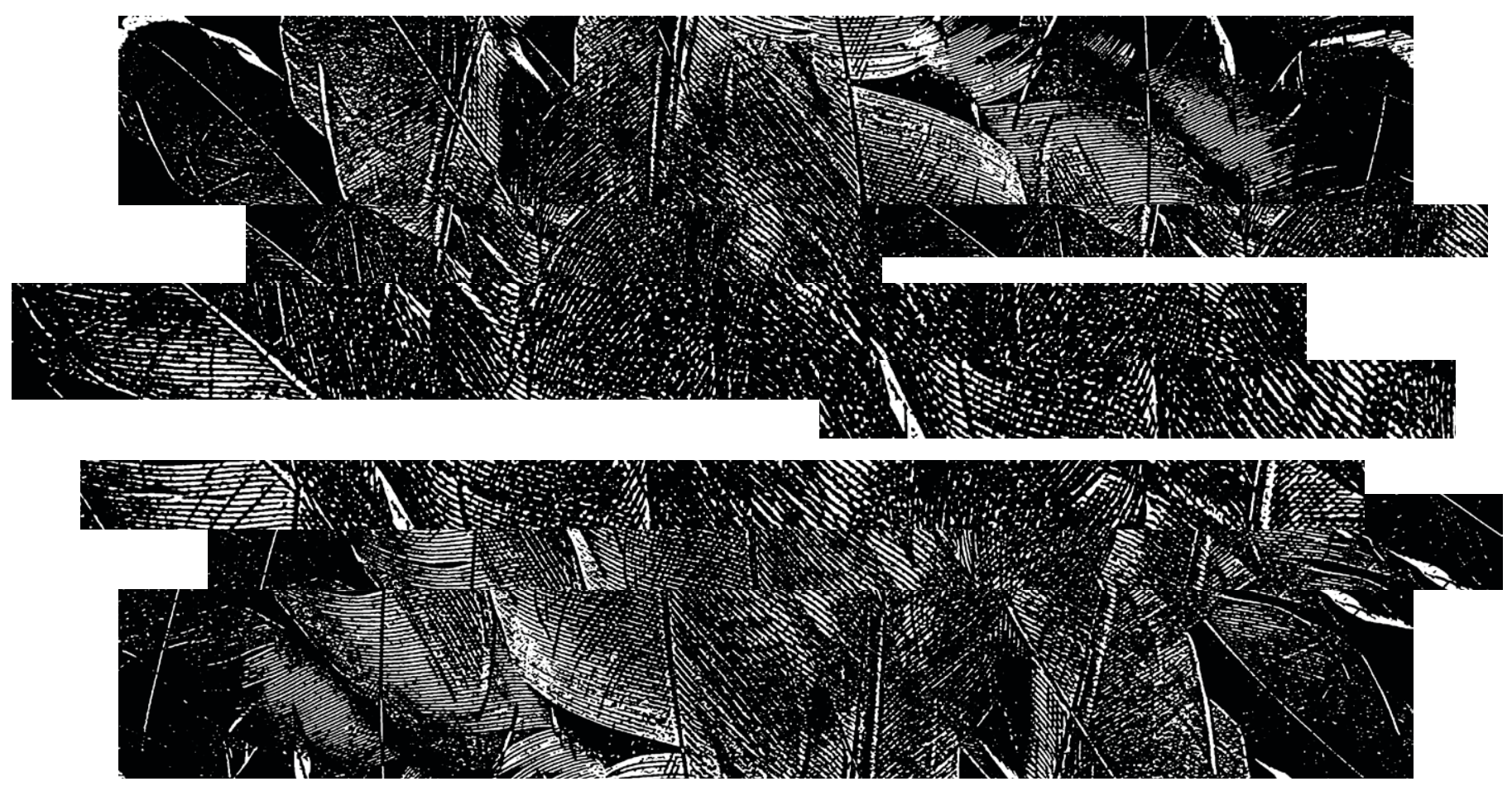


historia que se proponen contar. En el caso de Camila Loboguerro, existe una clara intención - manifestada por la misma directora- de reubicar el símbolo en el que se convirtió María Cano en la historia de la política en Colombia, su película identifica desde la cronología de la historia las visitas de María a las ciudades y municipios de Colombia y apuesta a una transformación de esta mujer, bautizada como "La flor del trabajo", en un ídolo del pueblo, tomando como objetivo vital de su película la agencia de María de los Ángeles Cano en el contexto político colombiano.

Si tenemos en cuenta que la formación académica e intelectual de Camila Loboguerrero transcurrió en Francia, estudiando cine y especializándose en montaje y sonido al lado de Jean Rouch, podemos entender sus decisiones en la realización de trabajos cercanos al Cinema Vérite. Sin embargo, aunque colaboró con los trabajos de crítica de arte de la escritora Marta Traba y con los procesos de creación artística de la pintora Beatriz González, Loboguerrero inició su camino en solitario, teniendo una fuerte influencia del cine documental de Marta Rodríguez, pero manteniéndose siempre en el terreno de la representación ficcional. La restitución histórica de la líder socialista que hace la directora se toma como uno de los textos primordiales para hablar de cine feminista en Colombia; sin embargo, Loboguerro insiste en que no es esta etiqueta la que quiere conseguir con su obra.

De acuerdo con Suárez (2009), quien propone una lectura de la película más cercana a un proyecto de cine social que pretende retratar y criticar la danza de los millones, resultante de la llegada de la economía de enclave a Colombia y su máxima estrategia, el sistema de república bananera, podemos analizar esta búsqueda de la película por volver a la discusión sobre el abuso de las multinacionales en Colombia. La cercanía de Camila Loboguerrero al contexto de las artes plásticas y escénicas da pistas acerca de las intenciones por exaltar la dimensión no solo política sino humana del personaje de María Cano, así como el valor de su producción literaria.

La película Confesión a Laura tiene una particularidad en su proceso de producción por estar basada en el guión de Alexandra Cardona - esposa del director-, quien de manera cercana supervisó aspectos de la puesta en escena y del sentido ideológico manifestado a través del diálogo de los personajes. En esta dupla Osorio-Cardona se identifica la cercanía de ambos hacia un tipo de cine más intimista, donde las cotidianidades de los personajes son determinantes para abordar discusiones más amplias como la filiación política, la convicción ideológica y la crítica hacia el pensamiento conservador, tan marcado desde la época de la colonia. El papel de la radio, los testimonios y registros escritos en la prensa y en las versiones de la historia sobre el asesinato de Gaitán, son puestos al servicio de la reconstrucción histórica que propone la película y, aunque se mantiene como telón de fondo, es primordial en la configuración del espacio íntimo de los personajes. Cada uno desde su rol, como productora y director de la película, se han caracterizado por la perspectiva crítica con la que analizan hechos asociados a la violencia de Estado. 
En Confesión a Laura se cuestiona el pensamiento y la autoridad del gobierno conservador de Mariano Ospina Pérez (1946-1950) a quien, sin expresarlo directamente, se le responsabiliza por la muerte de Gaitán. De igual forma, reafirmando el carácter de lucha y respaldando las ideas gaitanistas, la perspectiva desde la cual se analiza el fenómeno del asesinato del caudillo es celebrativa en todo momento. En este caso, la película propone un discurso alternativo del Bogotazo, donde se exaltan las bondades del pensamiento liberal, dado que es el que le permite a los personajes liberarse de las presiones externas, por parte del gobierno y del estado de sitio en el que se encuentra la ciudad.

En esta misma línea de los discursos alternativos de la historia, se encamina la película Carne de tu carne, cuestionando la hegemonía de los gobiernos conservadores en Colombia; Mayolo, a diferencia de Osorio, no toma partido sobre la conveniencia de un partido, se ocupa de explorar a través de la representación alegórica - de la cual nos ocuparemos más adelante- cómo el Estado ha tenido gran parte de la responsabilidad en los acontecimientos de la violencia y en el abuso de poder frente a la clase popular y los campesinos.

El ejercicio de revisar la historia de la violencia política de los años cincuenta por parte de los directores analizados llama la atención por dos aspectos: la constitución de este corpus fílmico como fuente de exploración alternativa frente al discurso histórico hegemónico que no ha pretendido indagar acerca de la responsabilidad del Estado en el conflicto y la violencia en Colombia, por lo menos en el siglo XX; y, en el mismo sentido, el punto en común que tienen los directores al representar la violencia de manera inferencial, experimentando y recurriendo a una optimización de los recursos del lenguaje audiovisual en sus relatos, lo que permite a su vez percibir tendencias narrativas, estéticas y estilos autorales en el cine colombiano, sin precedentes en la historia.

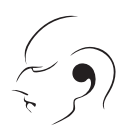




\section{Notas}

${ }^{1}$ Texto académico que hace parte de la investigación de maestría de la Universidad de Buenos Aires "Representaciones de la mujer en el cine colombiano de los ochenta: transformaciones con la aparición del discurso sobre la violencia “.

${ }^{2}$ Comunicadora social de la Universidad delValle, Magister en estudios de cine y teatro latinoamericano y argentino de la Universidad de Buenos Aires. Especialista en metodologías de la planeación audiovisual. Docente universitaria y del magisterio de Santiago en las cátedras de lenguaje e historia del cine (10 años). Directora de contenidos y productora en línea, canal regional Telepacífico (15 años). Investigadora, estudios de cine colombiano.

${ }^{3}$ Este período es trabajado de manera amplia por varios historiadores de la violencia en Colombia. Los textos de Daniel Pecaut (2012, pp. 45-75) y Enrique Pulecio Mejía (2000, pp. 159-161) coinciden en la nominación de este momento de fracturas políticas entre los partidos Liberal y Conservador, como el período de La Violencia, en el que el enfrentamiento radicalizado a sangre y fuego entre los militantes de ambos partidos se agudiza con el asesinato del líder político Jorge Eliécer Gaitán, el 9 de abril de 1948.

${ }^{4}$ En las décadas de los cuarenta y cincuenta se dio un giro temático en el cine colombiano relacionado con la semejanza a las producciones mexicanas y argentinas, cercanas a los géneros de la comedia ranchera y del melodrama tanguero. Las rancheras, boleros y tangos se sustituían por bambucos, y las historias giraban alrededor de la crisis de amores imposibles, las diferencias de clase y el paisajismo. Ya en la década del setenta, el intento por apoyar el cine nacional hace girar la producción en torno a la ley de sobreprecio que se dedica a la financiación de cortometrajes colombianos, los cuales persiguen fines publicitarios. En medio de este panorama, los personajes femeninos encarnan roles carcelarios de la mujer como parte de la sociedad patriarcal a la que pertenecen, donde los hombres dominan la esfera pública (Estado) y la privada (hogar).

${ }^{5}$ La sargento Matacho cuenta la historia de Rosalba Velásquez, una mujer víctima de la violencia, que escoge el camino de la venganza y queda atrapada en medio de la guerra en Colombia, durante la segunda mitad del Siglo XX. Es dirigida por William Ospina, cuenta con reconocimientos internacionales en festivales como el de Islantilla en Huelva y el Festival de Cine de Cali realizado en el 2014, donde tuvo su primera presentación pública en salas. Por problemas legales entre la coproducción realizada con México, el filme no ha sido presentado en el circuito de salas de cine nacionales.

6 “Mujeres en guerra”, el artículo de Carlos Eduardo Jaramillo (1995) para el compilado Las mujeres en la historia de Colombia, sitúa los principales hechos de violencia en los que se tienen pruebas de la participación de la mujer como miembro activo, ya sea de las filas liberales o conservadoras, y en escenarios combativos o de mero acompañamiento y apoyo moral. Los hallazgos y reflexiones de Jaramillo en torno al tema representan para nuestra investigación la columna de gran parte de los postulados establecidos, pues es precisamente este interés particular de la mujer en la escena de la violencia colombiana del siglo XX el que nos revela las transformaciones en las propuestas fílmicas colombianas de la década del ochenta.

${ }^{7}$ Coinciden en esta clasificación de las "tres violencias" en Colombia, que van a partir de la mitad del siglo XX, los autores Enrique Pulecio Mejía (2000), en su texto sobre Cine y violencia en Colombia y el escritor Geoffrey Kantaris (2008), quien se refiere al El Bogotazo como "la violencia original”.

${ }^{8}$ Campesinos es el tercer documental de Marta Rodríguez y Jorge Silva, estrenado en 1975, su idea surge luego de encontrarse con la experiencia de indígenas y campesinos en zonas donde la violencia y la guerra por la tenencia de la tierra los ha llevado a la lucha por la defensa de sus pueblos ancestrales.

${ }^{9}$ El libro del peruano Isaac León Frías (2013), El nuevo cine latinoamericano de los sesenta. Entre el mito político y la realidad fílmica, aborda la discusión sobre si esta nominación de la 
producción cinematográfica latinoamericana constituyó, evidentemente, un movimiento con elementos comunes, a pesar de las diferencias entre los contextos sociales, políticos y económicos de los diferentes países. "Que todos ellos, los ortodoxos y los heterodoxos, hicieron un cine nuevo es un hecho que — creo- no admite discusión. Por eso se puede afirmar con certeza que en esos años hubo una comprensible y legítima voluntad de renovación y, sobre todo, que se hizo un conjunto de películas con propuestas expresivas nuevas, que contribuyeron a enriquecer el abanico de la estética de la modernidad y el acervo cultural del país en que se hicieron y de la región en su conjunto. Eso es lo que permanece y lo que se debe rescatar, pero poniendo muy seriamente en duda — como lo hemos hechola existencia de un movimiento regional, de algo más que un proyecto concebido y alentado al calor de los debates políticos y culturales de esos años de la conmoción"

${ }^{10}$ La historia de El hombre de la sal es la de un campesino que se resiste a cambiar sus procedimientos de elaboración de la sal ante la modernización en las minas de Zipaquirá. Juana Suárez (2009) explica la relación de este trabajo con otros del documentalista norteamericano Robert Flaherty de la siguiente forma: "El interés de la cámara es el contraste entre el método artesanal de don Marcos Olaya y la modernización de las técnicas de producción. Para este procedimiento hay un especial detenimiento en las herramientas, reparando en ellas por medio de close - ups".

${ }^{11}$ Gabriela Samper, Carlos Álvarez y su esposa Julia, también vinculada con la actividad fílmica, fueron arrestados y llevados a prisión durante cinco meses en el año 1972, debido a especulaciones sobre su pertenencia a la Red Urbana del Ejército de Liberación Nacional.

${ }^{12}$ Además de las películas citadas, se debe reconocer el resultado del trabajo del escritor antioqueño Fernando Vallejo, quien antes de dedicarse a la profesión por la que mayormente se le conoce, realizó en México dos largometrajes: En la tormenta (1977) y Crónica roja (1979), los cuales fueron censurados en Colombia. Aunque representan un importante pronunciamiento de un director de cine al tema de la violencia, las películas estuvieron ausentes de la exhibición y por fuera de las catalogaciones sobre cine colombiano que se registran a nivel histórico, ya que se consideraron mexicanas.

\section{Referencias}

Jaramillo Castillo, C. E. (1995). Mujeres en guerra, participación de las mujeres en el conflicto. En Las mujeres en la historia de Colombia, Tomo I. Bogotá: Editorial Norma.

Álvarez, E. M. (1995). Mujeres y violencia, años 50. En Las mujeres en la historia de Colombia, Tomo I.Bogotá: Editorial Norma.

Acevedo, D. (1995). La Colombia contemporánea 1930-1990. En Las mujeres en la historia de Colombia, Tomo I. Bogotá:Editorial Norma.

León, I. (2013). El nuevo cine latinoamericano de los años sesenta: entre el mito político y la modernidad fílmica. Lima: Universidad de Lima, Fondo Editorial.

Suárez, J. (2009). Cinembargo Colombia. Ensayos críticos sobre cine y cultura. Cali: Editorial Universidad del Valle.

Pulecio Mejía, E. (2000). Arte y Violencia en Colombia desde 1948. En Cine y violencia en Colombia. Bogotá: Editorial Norma.

Pecaut, D. (2012). Orden y violencia. Medellín: Fondo Editorial Universidad EAFIT. (pp. 45-75)

Kantaris, G. (2008). El cine urbano y la tercera Violencia colombiana.Versiones, subversiones y representaciones del cine colombiano, XII Cátedra Anual de Historia Eduardo Restrepo Tirado. Ministerio de Cultura y Museo Nacional, Bogotá.

Montalva, F. (2010). Jorge Prelorán. El hombre es un creador. Recuperado de: http://tierraentrance. miradas.net/2010/10/ensayos/jorge-preloran-el-hombre-es-un-creador.html

Recibido: 15 de octubre de 2019 / Aprobado: 18 de noviembre de 2019 